\title{
Book review: The prehistoric apprentice: Investigating apprenticeship, know-how and expertise in prehistoric technologies; L’apprenti préhistorique: Appréhender l'apprentissage, les savoir-faire et l'expertise à travers les productions techniques des societies préhistoriques
}

\author{
Manek Kolhatkar
}

Université de Montréal, département d’anthropologie. Pavillon Lionel-Groulx, 3150 rue Jean-Brillant, H3T 1N8, Montréal, Québec, Canada. Email: manek.kolhatkar@umontreal.ca

The prehistoric apprentice: Investigating apprenticeship, know-how and expertise in prehistoric technologies; L'apprenti préhistorique: Appréhender l'apprentissage, les savoir-faire et l'expertise à travers les productions techniques des societies préhistoriques edited by Laurent Klaric

The Czech Academy of Sciences, Institute of Archaeology, Dolnověstonické Studie, Vol. 24, 2018, 374 pages. ISBN 978-80-7524-016-3. ISS 1801-7002

http://arub.avcr.cz/

Journal of Lithic Studies (2021) vol. 8, nr. 1, 2 p.

DOI: https://doi.org/10.2218/jls.5629

Published by the School of History, Classics and Archaeology, University of Edinburgh ISSN: 2055-0472. URL: http://journals.ed.ac.uk/lithicstudies/

Except where otherwise noted, this work is licensed under a CC BY 4.0 licence. 
Describing cultural change and variability and inferring sociocultural dynamics about past people and communities may be among archaeology's main goals as a field of practice. In this regard, the concept of skill has proved its usefulness to, time and again, expand the breath of archaeologists and lithic technologists' analyses. It covers a wide range of applications, from apprenticeship, cognition, paleo-sociology, spatial organization. It is one of the main causes for material culture variability, up there with raw material constraints, design, technological organization or cultural norms. Yet, while skill has certainly been the focus of some research in the last decades, it remains quite peripheral, when considering how central the concept should be to technological inquiries. Whatever the reasons may be, this book, edited by Laurent Klaric and fully bilingual (French and English), aims at changing that, and argues for skill to become a central concern in lithic technology. Its chapters do so strongly and the end-result is a book that should become a reference for lithic technologists, whatever their research interests or schools of thought may be.

Very briefly, the book's layout is as follows. The preface and the introduction sum up very briefly previous research on skill in stone knapping. Chapter 1 describes levels of skill on a bifacial assemblage from the Boxgrove site. Chapter 2 expounds a detailed methodology for quantifying skill and applies it on the lamellar assemblages of two Aurignacian (CorbiacVignoble 2 and Tercis) and two Gravettian sites (la Picardie and Solvieux). Chapter 3 furthers this quantification process with the blade assemblage from the Early Aurignacian site Tuto de Camalhot. Chapter 4 makes use of a simplified quantification methodology (when compared to the first chapters) to compare Chatelperronien and Early Aurignacian assemblages. Chapter 5 compares a handful of sites from the Early Aurignacian, Gravettian and Solutrean periods. Chapter 6 compares the microliths production patterns from the Magdalenian sites of Pincevent and Verberie. Chapter 7 describes the production of projectile elements from the Late Gravettian assemblages of Brassempouy and Grotte du Pape. Chapter 8 explore the link between the Middle and Upper Magdalenian sites of Le Morin, Villazette and Usine Henry (together with the Verberie site). Chapter 9 describes a protocol allowing for the technological analysis of engraving practices, applied here to Cantabrian and Pyrenean sites from the Middle Magdalenian. Chapter 10 and 11 turn the problem around and ask whether experts could also produce poorly manufactured cores, or flake assemblages otherwise attributed to novices. Finally, a post-face sums up the chapters, situates its contribution relative to foreign approaches (here, Anglo-Saxon ones) and rounds up the main strengths and weaknesses of the book.

The book's eleven chapters cover a wide range of technologies (bifacial, laminar, engraving), chronocultural contexts (from Lower Paleolithic to Neolithic periods) and depositional contexts (both high and lower resolution). They show that skill research can (and should) be conducted on a regular basis, how skill can help to expand the breath of lithic variability beyond the cultural norms that previous research has built, and how skill can be used as a conceptual tool for inter-assemblage and cross-cultural comparisons. To this end, one of the book's most important contribution may be to provide its readers with a set of tools for qualifying and quantifying lithic practices. This set combines the levels of descriptive details associated with the chaîne opératoire approach, with the focus on inter-assemblage comparability that quantifying methodologies strive for. However, this fusion of approaches is mostly seen in the first three to four chapters, where explicit methodological details (and problems) are fully addressed, while the remaining seven chapters make use of the more qualitative methodology that one is used to read in French lithic analysis. Each chapter presents high quality photographs, drawings, and useful tables of technological criteria with skill-related significance. In line with Perlès's closing chapter however, it is true that there is little reliance on psychomotricity, sociomotricity and communities of practice literature that would further strengthen the inferences made here. On the other hand, the more inductive 
approach favoured here could be seen as providing the reader with patterns and observations that should, in the future, be further investigated through experimentation protocols.

On a more general note, general, geographical and chronocultural information on the periods explored in the book would have been helpful for a reader unfamiliar with Paleolithic and Neolithic Western Europe. Maybe more importantly, a more general and theoretical chapter, similar to that written in 2014 by Peter Hiscock, could have been useful to provide the reader with a general understanding of the way skill could mesh empirical observations with anthropological narratives. It would have strengthened the case made here for bringing skill to the forefront of lithic analysis, or to suggest future lines of theoretical inquiry and formalization. Reading this book, three such lines came to my mind. First, in fully translating this book, foundations for building a bridge between various strands of thought (French and non-French) are laid. Second, exploring skill in stone knapping will require that intentionality be better defined, beyond the reproduction of specific cultural products and knapping methods, especially since research in psychomotricity, sociomotricity, phenomenology and anthropology have shown that it is a scalable and temporal concept. Third, skill could be integrated to the technological organization framework routinely used in North American archaeology, in the same way that the design concept was added to Binford's cultural inferences. The methodological formalizations seen in this book are certainly a necessary condition for this to happen and, consequently, to expand our deductive and inductive approaches to past practices. 